\title{
An Open-Label Pilot Study to Assess Honey Supplementation in Improving Lipid Profiles Among Chronic Smokers
}

Keywords: Antioxidant property; Chronic smokers; Honey; Lipid profiles

\begin{abstract}
Objectives: The objective of this study was to determine the effects of 12-week honey oral supplementation on fasting serum lipid profiles among chronic smokers.

Design: This study was a randomized, controlled, open-label clinical trial design.

Settings/location: Quit Smoking Clinic, University Sains Malaysia (USM) Hospital and Health Campus USM.

Subjects: Participants from non smokers ( $n=32$ ) and chronic smokers $(n=64)$ aged between $20-50$ years old were recruited. Participants from smoker group should have smoked at least 10 cigarettes per day for more than 5 years.
\end{abstract}

Interventions: The chronic smokers were further randomized into 2 groups namely smoker without honey $(n=32)$ and smoker with honey ( $20 \mathrm{~g} /$ day) for 12 weeks ( $n=32$ ).

Outcome measures: Outcome measures were triglyceride (TG), low-density lipoprotein (LDL), high-density lipoprotein (HDL) and total cholesterol (TC) levels between non smokers and chronic smokers at pre-intervention as well as the differences of these parameters between pre and post-intervention among smoker without honey and smoker with honey groups.

Results: At pre-intervention, chronic smokers had significantly lower HDL and higher TG, LDL and TC levels than non smokers. In smoker with honey group, TC and LDL levels were significantly reduced at postintervention than at pre-intervention. No significant changes were found in smoker without honey group.

Conclusion: This study may suggest that honey supplementation improves lipid profiles in chronic smokers which in turn may reduce the subsequent risk of cardiovascular diseases.

\section{Introduction}

Cigarette smoking has been reported as one of the major risk factors for the development of cardiovascular diseases. The other factors include hypertension, coronary artery disease, atherosclerotic vascular disease, myocardial infarction and stroke [1]. One of the major factors involved in initiating and accelerating the atherothrombotic process which contributes to the development of cardiovascular disease is an alteration in lipid profiles. Previous studies have found that cigarette smoke (CS) exposure is associated with increased lipolysis. It has been reported that the levels of total cholesterol (TC), low density lipoprotein (LDL) and triglycerides (TG) are significantly higher while the level of high density lipoprotein (HDL) is significantly lower in smokers compared to non smokers [2].

\section{Journal of}

Integrative Medicine \& Therapy

Wan Syaheedah Wan Ghazali and Mahaneem Mohamed*

Department of Physiology, School of Medical Sciences, Universiti Sains Malaysia, Kubang Kerian, Kelantan, Malaysia

*Address for Correspondence

Mahaneem Mohamed, Department of Physiology, School of Medical Sciences, Universiti Sains Malaysia, 16150, Kubang Kerian, Kelantan, Malaysia, Tel: +609-7676158; E-mail: mahaneem@usm.my

Submission: 01 January 2015

Accepted: 17 February 2015

Published: 23 February 2015

Reviewed \& Approved by: Dr. Harold H. Fain, Assistant Professor of Community Medicine, University of North Texas Health Science Center, USA

Although quit smoking is the best method to reduce the risk of cardiovascular diseases, there is still a need to reduce this risk among chronic smokers who fail to quit smoking by any means. This has led to an increased interest to investigate the possible beneficial effect of natural products in reducing this risk among smokers. Several studies have reported that supplementation of vitamin C-rich fruit juices for 26 days [3] as well as Quercitin-rich supplement for 10 weeks [4] significantly decreases TC and LDL levels in smokers. Honey is a natural product which contains carbohydrates such as fructose and glucose as well as organic acids, proteins, minerals and aromatic compounds [5]. It also contains antioxidants such as vitamins A and E [6], enzymes such as glucose oxidase and catalase [7], phenolic acids $[8,9]$, flavonoids $[10,11]$, as well as has antioxidant properties [12]. Honey has been shown to improve lipid profiles in animal and human studies. In animal study, previous study has found that rats have lower TG concentrations following 2 weeks of purified diets containing $65 \%$ carbohydrate from honey compared with a fructose/ glucose mixture [13]. Meanwhile, the HDL level is significantly increased in adult Sprague Dawley rats fed with $10 \%$ powdered honey ad libitum with $21 \%$ water for 52 weeks [14]. In human study, supplementation of $70 \mathrm{~g}$ of honey for 30 days among overweight and obese individuals significantly reduces TC, LDL and TG as well as increases HDL levels [15]. The level of LDL is also reduced in patients with hyper lipidemia taking $75 \mathrm{~g}$ of honey supplementation orally for 15 days [16].

However, to date, no study has been reported to determine whether honey supplementation is able to improve lipid profiles among smokers. Therefore, the aim of this an open-label pilot study was to determine the possible role of honey in improving the lipid profiles among smokers.

\section{Research Design and Methods}

\section{Design and subjects}

This study was a randomized, controlled, open-label clinical trial design and approved by the Human Research Ethics Committee of 
Citation: Wan Ghazali WS, Mohamed M. An Open-Label Pilot Study to Assess Honey Supplementation in Improving Lipid Profiles Among Chronic Smokers. J Integrative Med Ther. 2015;2(1): 5.

ISSN: 2378-1343

Universiti Sains Malaysia (USM) (approval code: JEPeM [243.3.(6)]. The study involved 32 male non smokers and 64 male smokers aged between 20 - 50 years old. The participants from non smoker group were recruited from USM staff in the Health Campus while participants from smoker group were volunteers or patients recruited from the Quit Smoking Clinic, USM Hospital and Health Campus. Participants from the non smoker group should have no history of smoking and exposure to environmental tobacco smoke. Meanwhile, participants from smoker group should have smoked at least 10 cigarettes per day for more than 5 years. Participants who were obese $\left(\mathrm{BMI}>30 \mathrm{~kg} / \mathrm{m}^{2}\right)$, taking alcohol, regularly taking dietary supplements and/or multivitamins 3 months prior to the study or had history of cardiovascular diseases that might interfere with the study objectives were excluded. Body mass index (BMI) were measured and recorded from each participant. Participants who had fulfilled the criteria were briefed concerning the nature of the study and informed consent was taken. Randomization was computer generated, and smoker group was then randomly assigned into 2 groups namely smoker with honey $(\mathrm{n}=32)$ and smoker without honey $(\mathrm{n}=32)$ groups.

\section{Intervention}

All participants were asked to maintain their current activity levels which include diet and exercise during the study. The honey group received $20 \mathrm{~g} /$ day of honey orally for 12 weeks. Pure honey namely Tualang honey was supplied from Federal Agricultural \& Agro Based Industry, Malaysia. Blood was obtained from all participants during the initial visit (week 0) for the pre-intervention status assessment. Honey supplementation was then administered to the smoker with honey group after blood sampling at weeks 0,4 and 8 . The participants were required to return the empty sachet to ensure compliance and any possible adverse effects of supplementation were monitored at weeks 4, 8 and 12. Post-intervention status was reassessed after 12 weeks. As for the participants from non smoker group, blood was collected only at pre-intervention for baseline comparison on the status of lipid profiles.

\section{Blood collection and sample preparation}

A total of $3 \mathrm{~mL}$ of fasting venous blood was obtained from all participants at pre-intervention and from participants of both smoker groups at post-intervention. The blood was collected into plain tubes.

\section{Determination of lipid profiles}

The plain tubes for lipid profiles was sent immediately to the BP Clinical Lab Sdn Bhd, Kelantan, Malaysia for determination of serum TC, LDL, HDL and TG levels using a clinical chemistry analyzer (Architect Ci8200, USA). Serum TC, LDL and TG were measured using enzymatic-colorimetric method while serum HDL was measured using enzymatic direct determination by elimination method.

\section{Statistical analyses}

Results were analysed using PASW Statistics version 20. Independent $t$-test was used to analyse the difference of preintervention lipid profiles status between non smoker and smoker groups. The baseline and changes over a 12 -week intervention period in each group of smokers were assessed by paired $t$-test for normally distributed data. A value of $p<0.05$ was considered statistically significant. Data are presented as mean and standard error of mean (SEM).

\section{Results}

\section{Characteristics of the subjects}

Table 1 shows the baseline characteristics of the participants. There were no significant differences in mean age and height between both non smoker and smoker groups. On the other hand, smoker group had significantly higher levels of mean weight and mean body mass index (BMI) compared to non smoker group.

\section{Pre-intervention level and changes (between pre and post- intervention) of lipid profiles among subjects}

The levels of lipid profiles at pre-intervention are presented in Table 2. The level of mean serum TG, LDL and TC at pre-intervention were significantly higher in smoker group compared to non smoker group. On the other hand, the level of mean serum HDL at preintervention was significantly lower in smoker group compared to non smoker group.

The levels of lipid profiles at pre and post-intervention in smoker with honey and smoker without honey groups are presented in Table 3. At post-intervention, the changes of mean serum TG in both smoker groups were not statistically significant. On the other hand, in smoker with honey group, the mean serum LDL was significantly reduced after 12 weeks. Meanwhile, in smoker without honey group, no significant difference was observed for the level of mean serum LDL. Furthermore, the change in the level of HDL after 12 weeks was not statistically significant in both smoker groups. In addition, there was a significant reduction for TC level in smoker with honey group while no significant change was observed in smoker without honey group after 12 weeks.

\section{Discussion}

In the present study, the mean age and mean height between

Table 1: Characteristics of the participants between non smokers and smokers groups.

\begin{tabular}{|l|c|c|}
\hline & $\begin{array}{c}\text { Non smokers } \\
(\mathbf{n = 3 2})\end{array}$ & $\begin{array}{c}\text { Smokers } \\
(\mathbf{n = 6 4 )}\end{array}$ \\
\hline Age (years) & $35.16(1.50)$ & $38.38(0.97)$ \\
\hline Height $(\mathrm{cm})$ & $166.81(0.80)$ & $168.09(0.92)$ \\
\hline Weight $(\mathrm{kg})$ & $65.34(1.80)$ & $70.98(1.46)^{*}$ \\
\hline BMl $\left(\mathrm{kg} / \mathrm{m}^{2}\right)$ & $23.30(0.61)$ & $26.09(0.58)^{\star}$ \\
\hline
\end{tabular}

Data are presented as mean (SEM). BMI: Body Mass Index.

${ }^{*} p<0.05$ compared to non smokers (Independent $t$-test)

Table 2: Pre-intervention lipid profiles between non smoker and smoker group.

\begin{tabular}{|l|c|c|}
\hline & $\begin{array}{c}\text { Non smokers } \\
(\mathbf{n = 3 2})\end{array}$ & $\begin{array}{c}\text { Smokers } \\
(\mathbf{n = 6 4 )}\end{array}$ \\
\hline $\mathrm{TG}(\mathrm{mmol} / \mathrm{L})$ & $1.06(0.08)$ & $1.53(0.09)^{*}$ \\
\hline $\mathrm{LDL}(\mathrm{mmol} / \mathrm{L})$ & $2.80(0.11)$ & $3.68(0.11)^{\star}$ \\
\hline $\mathrm{HDL}(\mathrm{mmol} / \mathrm{L})$ & $1.56(0.05)$ & $1.24(0.02)^{\star}$ \\
\hline $\mathrm{TC}(\mathrm{mmol} / \mathrm{L})$ & $4.90(0.12)$ & $5.64(0.13)^{*}$ \\
\hline
\end{tabular}

Data are presented as mean (SEM). TG: Triglyceride; LDL: Low Density Lipoprotein; HDL: High Density Lipoprotein; TC: Total Cholesterol.

${ }^{*} p<0.001$ compared to non smokers (Independen $t$-test) 
Table 3: Pre-intervention and post-intervention lipid profiles in chronic smokers.

\begin{tabular}{|l|c|c|c|}
\hline & \multicolumn{2}{|c|}{ Smokers with honey $(\mathbf{n = 3 2})$} & \multicolumn{2}{|c|}{ Smokers without honey (n=32) } \\
\hline TG $(\mathrm{mmol} / \mathrm{L})$ & Pre-intervention & Post-intervention & \multicolumn{2}{|c|}{ Pre-intervention } \\
\hline $\mathrm{LDL}(\mathrm{mmol} / \mathrm{L})$ & $1.53(0.12)$ & $1.66(0.13)$ & $1.53(0.12)$ \\
\hline $\mathrm{HDL}(\mathrm{mmol} / \mathrm{L})$ & $3.84(0.17)$ & $3.60(0.18)^{*}$ & $3.54(0.14)$ \\
\hline TC $(\mathrm{mmol} / \mathrm{L})$ & $1.27(0.03)$ & $1.22(0.04)$ & $1.68(0.12)$ \\
\hline
\end{tabular}

Data are presented as mean (SEM). TC: Total Cholesterol; TG: Triglyceride; HDL: High Density Lipoprotein; LDL: Low Density Lipoprotein.

${ }^{*} p<0.05$ compared to pre-intervention in the corresponding group (Paired $t$-test)

smoker and non smoker groups revealed no significant differences. However, the level of BMI among smokers in the present study was significantly higher compared to non smokers. This finding could be contributed by the body weight among smokers which was significantly higher than non smokers. The greater body weight in smokers could be due to less intake of vegetables and fruits [17], unhealthy patterns of nutrient intake [18] as well as less engage in physical activity compared to non smokers [19]. In addition, previous study has suggested that the greater body weight among smokers could be also due to high alcohol intake [20] which merit further study.

The level of TG, which is the major energy reserve in the body, was significantly higher in smokers compared to non smokers at pre-intervention in the present study. This finding is similar with other studies $[2,21,22]$ whereby the levels of TG is significantly higher in smokers compared to non smokers. The metabolism of TG is regulated by the action of lipoprotein lipase, an enzyme which is responsible for catalyzing TG hydrolysis and clearing of TG from the blood. It is suggested that this enzyme is also reduced by nicotine which is present in CS. It has been demonstrated that the activity of lipoprotein lipase at the skeletal muscle is reduced in smokers compared to non smokers [23]. Thus, in the present study, the higher TG level could be possibly due to the reduced lipoprotein lipase activity by nicotine which in turn may lead to impaired TG clearance in smokers. At post-intervention, the smoker group receiving honey supplementation showed no significant difference in the level of TG. This result is supported by animal studies that shows no significant difference in the level of TG when rats are fed either with $10 \%$ honey or sucrose-based diet for 6 weeks [24] or 52 weeks [14]. On the other hand, consumption of honey for 8 weeks among diabetic patients [25] and 4 weeks among obese subjects [26] significantly reduces the level of TG. Reduced TG level is also obtained after honey supplementation for 15 days to participants with hyper triglyceridemia [15]. The inconsistencies in these studies compared to the present study could be due to the difference in characteristics of the participants.

In the present study, the level of LDL, the major carrier of cholesterol in the circulation, was significantly higher in smokers compared to non smokers at pre-intervention, indicating the metabolic effects of smoking. This finding corresponds to earlier studies $[21,22,27,28]$ whereby the levels of LDL is significantly higher in smokers compared to non smokers. The significantly higher level of LDL might be contributed by the presence of insulin resistance among smokers [29]. Insulin resistance could possibly due to impaired glucose uptake by the peripheral organs as a consequence of CS [30]. Insulin resistance at the adipocyte could lead to increased free fatty acids that released into the circulation which subsequently, leads to increased influx of free fatty acids into the liver. This might stimulate the hepatic secretion of VLDL [31] which provides the precursor for LDL formation. Apart from that, stimulation of nicotine causes an increase in adrenaline release by the adrenal cortex leading to increased lipolysis. This may contribute to increased free fatty acids concentrations in smokers [32]. Free fatty acid is a stimulant of hepatic secretion for VLDL and thus, contributes to the increased level of LDL [33]. Following 12 weeks of honey supplementation, the result revealed a significant reduction in the level of LDL which is consistent with previous studies [16,25]. Previous study has observed that the level of LDL is reduced in patients with hyperlipidemia by taking $75 \mathrm{~g}$ of honey supplementation for 15 days [16]. Furthermore, honey supplementation among diabetic type 2 patients for 8 weeks [25] and obese subjects for 4 weeks [26] significantly reduces the level of LDL. It is suggested that the reduction in LDL could possibly due to the modulation of lipoprotein lipase activity by honey in which lipoprotein lipase hydrolyzes TG in chylomicrons [34]. Thus, reduction in lipoprotein could be modulated by influencing the activity of lipoprotein lipase. Apart from that, it is also reported that honey might improve the LDL metabolism through LDL receptor at hepatic level [26]. The beneficial effect of honey used in the present study in reducing LDL level among smokers corresponds to the previous study which shows a significantly reduced level of LDL with consumption of quercetin-rich supplement for 10 weeks [4]. Quercetin is a flavonoid and has been reported to induce a reduction in de novo synthesis of fatty acid and TG leading to a decrease formation of VLDL and subsequent LDL in hepatocytes of normal rats [35]. Honey is reported to have a wide range of flavonoids such as kaempferol, catechin, naringenin, apigenin and luteolin [11] as well as quercetin [36]. Therefore, the effect of honey in reducing LDL in the present study could be due to the effect of flavonoids present in honey which may reduce the synthesis of de novo fatty acid and TG leading to decreased VLDL and subsequent LDL formation in the liver which need further studies.

In the present study, the level of HDL, the major cardioprotective lipoprotein was significantly lower in smokers compared to non smokers at pre-intervention which is in accordance with previous studies [28,37,38]. Furthermore, Criqui et al. has found that smokers have significantly lower level of HDL compared to non smokers suggesting a possible causal relationship between CS and low HDL level [39]. In the present study, CS may cause increases in catecholamine levels which subsequently lead to an increase in serum estradiol level in male smokers [40]. CS may cause an increase in 2-hydroxylation pathway of estradiol metabolism which 
Citation: Wan Ghazali WS, Mohamed M. An Open-Label Pilot Study to Assess Honey Supplementation in Improving Lipid Profiles Among Chronic Smokers. J Integrative Med Ther. 2015;2(1): 5.

subsequently may affect synthesis of apolipoprotein in the liver. This in turn may contribute to the reduction in HDL level among smokers [41]. In the present study, the level of HDL after 12 weeks of honey supplementation showed no significant difference. This finding is in accordance with an animal study in which there is no significant difference in HDL level between the rats fed honey and sucrose-based diets for 33 days [42]. Furthermore, rodent fed with honey for 6 weeks shows no significant difference in the level of HDL. However, several studies shows increased levels of HDL after supplementation of honey $[14,25]$. Consumption of honey for 8 weeks among diabetic type 2 patients [25] and 4 weeks among obese subjects [26] significantly reduces the level of HDL. In animal study, it is observed that rats fed a diet with honey have higher HDL levels than rats fed with sucrose or sugar free based diet after 52 weeks [14]. The inconsistent finding could be contributed by the type of honey and the characteristics of the study participants.

The level of TC, which is defined as the sum of HDL, LDL and VLDL, was significantly higher in smokers compared to non smokers. In the present study, the higher level of TC could be contributed by the significantly higher level of LDL in smokers compared to non smokers. Furthermore, the significantly higher level of TC among smokers in previous studies [21,38] may suggest that cigarette smoking adversely affects serum lipid which further increases the risk for cardiovascular morbidity and mortality. On the other hand, there is no significant difference in TC level between smokers and non smokers in previous study [43] which could be due to factors such as diet, physical activity, body weight, waist/ hip ratio, psychosocial conditions [44] and genetic variation [45]. Furthermore, in the present study, the level of TC revealed a significant reduction in smoker group receiving honey supplementation for 12 weeks which is consistent with previous studies [4,25]. In a study involving diabetic type 2 patients subjected to honey for 8 weeks, there is a significant decrease in TC level [25]. Furthermore, Lee et al. has reported that consumption of quercetin-rich supplement for 10 weeks significantly reduces the level of TC among male smokers [4]. In animal study, it is reported that quercetin increases fecal excretion of cholesterol causing a decrease in the levels of serum cholesterol in rats [46]. Apart from that, quercetin may reduce the synthesis of hepatic fatty acid and inhibit biosynthesis of cholesterol in rat hepatocytes [47]. Honey has been reported to have flavonoids such as kaempferol, catechin, naringenin, apigenin and luteolin [11] as well as quercetin [36]. Thus, the significantly reduced level of TC found in smoker with honey group in the present study could be partly explained by the effect of quercetin, which is present in honey, on lipid metabolism among smokers.

\section{Conclusion}

In conclusion, chronic smokers had significantly higher levels of TG, LDL and TC as well as significantly lower level of HDL. Supplementation of Tualang honey for 12 weeks significantly reduced the level of LDL and TC among chronic smokers. These findings may suggest that honey supplementation can be used among chronic smokers in order to protect their health from the risk of having cardiovascular diseases which could be further evaluated with larger number of participants.

\section{References}

1. Ockene IS, Miller NH (1997) Cigarette smoking, cardiovascular disease, and stroke: a statement for healthcare professionals from the American Heart Association. American Heart Association Task Force on Risk Reduction. Circulation 96: 3243-3247.

2. Rao CH, Emmanuel SY (2013) The effect of chronic tobacco smoking and chewing on the lipid profile. J Clin Diagn Res 7: 31-34.

3. Alvarez-Parrilla E, De La Rosa LA, Legaretta P, Saenz L, Rodrigo-Garcia J, et al. (2010) Daily consumption of apple, pear and orange juice differently affects plasma lipids and antioxidant capacity of smoking and non-smoking adults. Int J Food Sci Nutr 61: 369-380.

4. Lee KH, Park E, Lee HJ, Kim MO, Cha YJ, et al. (2011) Effects of daily quercetin-rich supplementation on cardiometabolic risks in male smokers. Nutr Res Pract 5: 28-33.

5. Bogdanov S, Jurendic T, Sieber R, Gallman P (2008) Honey for nutrition and health: a review. J Am Coll Nutr 27: 677-689.

6. Al-Waili NS (2003) Effects of daily consumption of honey solution on hematological indices and blood levels of minerals and enzymes in normal individuals. J Med Food 6: 135-140.

7. Gheldof N, Wang XH, Engeseth NJ (2002) Identification and quantification of antioxidant components of honeys from various floral sources. J Agric Food Chem 50: 5870-5877

8. Michalkiewicz A, Biesaga M, Pyrzynska K (2008) Solid-phase extraction procedure for determination of phenolic acids and some flavonols in honey. $J$ Chromatogr A 1187: 18-24.

9. Pyrzynska K, Biesaga M (2009) Analysis of phenolic acids and flavonoids in honey. Trends Analyt Chem 28: 893-902.

10. Yao L, Jiang Y, D’Arcy B, Singanusong R, Datta N, et al. (2004) Quantitative high-performance liquid chromatography analyses of flavonoids in Australian Eucalyptus honeys. J Agric Food Chem 52: 210-214.

11. Khalil MI, Alam N, Moniruzzaman M, Sulaiman SA, Gan SH (2011) Phenolic acid composition and antioxidant properties of Malaysian honeys. J Food Sci 76: C921-C928.

12. Mohamed M, Sirajudeen KNS, Swamy M, Yaacob NY, Sulaiman SA (2010) Studies on the antioxidant properties of Tualang honey of Malaysia. Afr J Trad CAM 7: 59-63.

13. Busserolles J, Gueux E, Rock E, Mazur A, Rayssiguier Y (2002) Substituting honey for refined carbohydrates protects rats from hypertriglyceridemic and prooxidative effects of fructose. J Nutri 132: 3379-3382.

14. Chepulis L, Starkey N (2008) The long-term effects of feeding honey compared with sucrose and a sugar-free diet on weight gain, lipid profiles, and dexa measurements in rats. J Food Sci 73: H1-H7.

15. Yaghoobi N, AI-Waili N, Ghayour-Mobarhan M, Parizadeh SM, Abasalti Z, et al. (2008) Natural honey and cardiovascular risk factors; effects on blood glucose, cholesterol, triacylglycerole, CRP, and body weight compared with sucrose. ScientificWorldJournal 8: 463-469.

16. Al-Waili NS (2004) Natural honey lowers plasma glucose, C-reactive protein, homocysteine, and blood lipids in healthy, diabetic, and hyperlipidemic subjects: comparison with dextrose and sucrose. J Med Food 7: 100-107.

17. Serdula MK, Byers T, Mokdad AH, Simoes E, Mendlein JM, et al. (1996) The association between fruit and vegetable intake and chronic disease risk factors. Epidemiology 7: 161-165.

18. Thompson RL, Margetts BM, Wood DA, Jackson AA (1992) Cigarette smoking and food and nutrient intakes in relation to coronary heart disease. Nutr Res Rev 5: 131-152.

19. Kvaavik E, Meyer HE, Tverdal A (2004) Food habits, physical activity and body mass index in relation to smoking status in 40-42 year old Norwegian women and men. Prev Medicine 38: 1-5.

20. Bien TH, Burge R (1990) Smoking and drinking: a review of the literature Subst Use Misuse 25: 1429-1454 
Citation: Wan Ghazali WS, Mohamed M. An Open-Label Pilot Study to Assess Honey Supplementation in Improving Lipid Profiles Among Chronic Smokers. J Integrative Med Ther. 2015;2(1): 5.

21. Haj MD, Ezzaher A, Araoud M, Neffati F, Douki W, et al. (2010) Paraoxonase 1 (PON1) activity and lipid parameters in Tunisian smokers. Ann Biol Clin 68 : $143-147$

22. Alharbi WD (2011) Influence of cigarette smoking on lipid profile in male university students. Pak J Pharma 28: 45-49.

23. Chajek-Shaul T, Berry EM, Ziv E, Friedman G, Stein O, et al. (1990) Smoking depresses adipose lipoprotein lipase response to oral glucose. Eur J Clin Invest 20: 299-304.

24. Chepulis $L$ (2007) The effect of honey compared to sucrose, mixed sugars, and a sugar-free diet on weight gain in young rats. J Food Sci 72: S224-S229.

25. Bahrami M, Ataie-Jafari A, Hosseini S, Foruzanfar MS, Rahmani M, et al (2009) Effects of natural honey consumption in diabetic patients: an 8-week randomized clinical trial. Int J Food Sci Nutr 60: 618-626.

26. Mushtaq R, Mushtaq R, Khan ZT (2011) Effects of natural honey on lipid profile and body weight in normal weight and obese adults: a randomized clinical trial. Pak J Zool 43: 161-169.

27. Meenakshisundaram R, Rajendiran C, Thirumalaikolundusubramanian $P$ (2010) Lipid and lipoprotein profiles among middle aged male smokers: a study from southern India. Tob Induc Dis 8: 11.

28. Guedes DP, Guedes JERP, Barbosa DS, Oliveira JA (2007) Tobacco use and plasma lipid-lipoprotein profile in adolescents. Rev Assoc Med Bras 53 59-63.

29. Craig WY, Palomaki GE, Haddow JE (1989) Cigarette smoking and serum lipid and lipoprotein concentrations: an analysis of published data. BMJ 298 : 784-788.

30. Attvall S, Fowelin J, Lager I, Schenck H, Smith U (1993) Smoking induces insulin resistance-a potential link with the insulin resistance syndrome. J Intern Med 233: 327-332.

31. Ginsberg HN (2000) Insulin resistance and cardiovascular disease. J Clin Invest 106: 453-458.

32. Kershbaum A, Khorsandian R, Caplan RF, Bellet S, Feinberg LJ (1963) The role of catecholamines in the free fatty acid response to cigarette smoking. Circulation 28: 52-57.

33. Kohout M, Kohoutova B, Heimberg M (1971) The regulation of hepatic triglyceride metabolism by free fatty acids. J Biol Chem 246: 5067-5074.

34. Goldberg IJ (1996) Lipoprotein lipase and lipolysis: central roles in lipoprotein metabolism and atherogenesis. J Lipid Res 37: 693-707.
35. Gnoni G, Paglialonga G, Siculella L (2009) Quercetin inhibits fatty acid and triacylglycerol synthesis in rat-liver cells. Eur J Clin Invest 39: 761-768.

36. Hussein SZ, Yusoff KM, Makpol S, Yusof YAM (2011) Antioxidant capacities and total phenolic contents increase with gamma irradiation in two types of Malaysian honey. Molecules 16: 6378-6395.

37. Arslan E, Yakar T, Yavasoglu I (2008) The effect of smoking on mean platelet volume and lipid profile in young male subjects. Anadolu Kardiyol Derg 8: 422-425.

38. Batic-Mujanovic O, Beganlic A, Salihefendic N, Pranjit N, Kusljugic Z (2008) Influence of smoking on serum lipid and lipoprotein levels among family medicine patients. Med Arh 62: 264-267.

39. Criqui MH, Wallace RB, Heiss G, Mishkel M, Schonfeld G, et al. (1980) Cigarette smoking and plasma high-density lipoprotein cholesterol. The Lipid Research Clinics Program Prevalence Study. Circulation 62: IV70-76.

40. Klaiber EL, Broverman DM, Dalen JE (1984) Serum estradiol levels in male cigarette smoker. Am J Med 77: 858-862.

41. Michnovicz JJ, Hershcopf RJ, Haley NJ, Bradlow HL, Fishman J (1989) Cigarette smoking alters hepatic estrogen metabolism in men: implications for atherosclerosis. Metabolism 38: 537-541.

42. Nemoseck TM, Carmody EG, Furchner-Evanson A, Gleason M, Li A, et al. (2011) Honey promotes lower weight gain, adiposity, and triglycerides than sucrose in rats. Nutr Res 31: 55-60.

43. Saengdith $P$ (2008) Effects of cigarette smoking on serum lipids among priests in bangkok. J Med Assoc Thai 91: S41-44

44. Thelin A, Stiernstrom EL, Holmberg S (2001) Blood lipid levels in a rural male population. J Cardiovasc Risk 8: 165-174.

45. Senti M, Aubo C, Bosch M (1998) The relationship betwen smoking and triglyceride-rich lipoproteins is modulated by genetic variation in the glycoprotein Illa gene. Metabolism 47: 1040-1041.

46. Igarashi K, Ohmuma M (1995) Effects of isorhamnetin, rhamnetin, and quercetin on the concentrations of cholesterol and lipoperoxide in the serum and liver and on the blood and liver antioxidative enzyme activities of rats. Biosci Biotechol Biochem 59: 595-601.

47. Glasser G, Graefe EU, Struck F, Veit M, Gebhardt R (2002) Comparison of antioxidative capacities and inhibitory effects on cholesterol biosynthesis of quercetin and potential metabolites. Phytomedicine 9: 33-40.
Copyright: ๑ 2015 Wan Ghazali WS, et al. This is an open access article distributed under the Creative Commons Attribution License, which permits unrestricted use, distribution, and reproduction in any medium, provided the original work is properly cited.

\section{Acknowledgements}

The authors gratefully acknowledge Short Term Grant, Universiti Sains Malaysia (Grant No: 304/PPSP/61312034). 